\title{
Effects of Ball Milling Conditions on Breakage Response of Baban Tsauni (Nigeria) Lead-Gold Ore.
}

\author{
E.A.P. Egbe ${ }^{1,1^{*}}$ \\ ${ }^{I}$ Mechanial Engineering Department, Federal University of Technology, Minna, Nigeria.
}

\begin{abstract}
The effects of ball milling conditions on breakage response of Baban Tsauni (Nigeria) lead-gold ore was examined in this research work. The three factors considered were, the grinding media mass to ore sample mass ratio, the grinding time and the ball mill speed. The breakage response measured in terms of cumulative per cent mass passing the liberation size increased with increase in media mass to sample mass ratio and reached optimum at a ratio of 10:1. The response per unit time decreased as the grinding time was increased gradually from 2 minutes to 10minutes, thereby indicating that long grinding circuits were poor in performance. The optimum ball milling speed of the ore was found to be $82.9 \%$ of the critical mill speed. This work established a rational approach in the choice of grinding speed. The effects of the three parameters on generation of fines were less pronounced.
\end{abstract}

Key words: energy, fines, grindability, optimum, particle size.

\section{Introduction}

Cumminution is an energy intensive process and a search for conditions that affect performance will lead to conservation of energy. The Bond's Work Index is generally used as a measure of the resistance of a material to breakage [1], [2], [3], [4]. The standard Bond grindability test is carried out under specified conditions of mill volume, mill speed, feed particle size, a circulating load of $250 \%$ and a control sieve size that depend on the target particle size [2], [5]. The Bond's work index is highly sensitive to the control sieve size and circulating load [6], [7], [8], [9], [10], [11], [12]. The foregoing indicates that the performance of a grinding mill is affected by the operating conditions in the mill.

Excessive grinding of an ore increases energy costs and also leads to production of very fine untreatable slime particles which may be lost into the tailings and production of fines is affected by mill conditions. Thus grinding is a compromise between clean (high-grade) concentrates, operating costs, and losses of fine minerals [3].

\subsection{Literature review}

The effect of grinding conditions on the response of an ore can be studied by varying one condition at a time and deducing information from the data [13]. Man [5] indicates that mill speed affects energy consumption and throughput. The ball size influence mill throughput, power consumption and progeny size [14], [15]. It is reported by [16] that each grain size has an optimum ball size. Energy wastage and drop in throughput are the consequence of deviation from optimum conditions [17], [18], [19].

The critical grinding speed $\left(\mathrm{V}_{\mathrm{c}}\right)$ of a ball mill (in rpm) is given by [20] as:

$$
V_{c}=\frac{42.3}{\sqrt{(D-d)}}
$$

where $\mathrm{D}$ is the mill diameter and $\mathrm{d}$ is the ball diameter. The critical speed denotes the speed to be avoided. It does not indicate the optimum speed. The standard Bond's test is performed at a mill speed of 0.91 Vc [5]. Sahoo and Roy [21] observed that ball mills usually operate at speed ranging from $65 \%$ to $75 \%$ of the critical speed. Adoption of different choice of mill speed by researchers is common $\{0.752 \mathrm{Vc}$ [2]; $0.8 \mathrm{Vc}$ [22]; $0.86 \mathrm{Vcc}$ [23] and $0.85 \mathrm{Vc}$ [19]\}. The foregoing suggests that further research work is required to determine the optimum ball milling speed for each ore.

Overloading of the mill leads to accumulation of fines at the toe of the mill, which result in cushioning effect on the balls upon impact. Contrarily when the material load is low, excessive ball to ball contact retard the rate of breakage [20].

The optimum breakage response of an ore requires the maximum production of particles of the desired size while minimizing the production of untreatable fines. Thus the effects of milling conditions on response must be known in addition to the grindability of an ore. 


\section{Materials and experimental procedures}

About 20kg of ore samples from Baban Tsauni lead-gold ore was used for this research work. An initial sample preparation aimed at ensuring a homogeneous feed for subsequent test runs was carried out. The crushed samples from the jaw crusher /roll crusher ( in that order) were subjected to the same grinding conditions of mill speed, ore mass to ball mass ratio, ball size and grinding time of 10minutes. The products of this batch milling operations were mixed thoroughly and passed through a Jones riffling sampler, until sets of $472 \mathrm{~g}$ samples were obtained.

The critical speed of the mill was determined by applying (1). The first response measured in all the experiments was the percentage of the product mass which passed the liberation size (355 microns) while the second response was the amount of fines generated in terms of per cent mass passing $50 \mu \mathrm{m}$.

The mill was charged with steel balls and the ore materials in layers, starting with the balls. Half a kilogram of the feed materials was used for each experiment. The mill was closed and placed on the rollers and the mill started. After grinding, the mill content was discharged unto a stainless steel bow and the balls were removed. A brush was used to clean the balls so that no material is lost. The content of each sieve fraction was weighed and recorded.

\subsection{The effect of ball mass to sample mass ratio on breakage response}

The grinding speed was kept constant at $101 \mathrm{rpm}$, the holding time at 10minutes, and the ball size at $25 \mathrm{~mm}$ diameter. The ball mass to sample mass ratio of 2:1, 4:1, 6:1, 8:1, 10:1 and 12:1 were used. The product of each test run was subjected to sieving for 15 minutes and the cumulative per cent mass passing $355 \mu \mathrm{m}$ and $50 \mu \mathrm{m}$ were determined.

\subsection{The effect of holding time on breakage response}

The mill speed was maintained at 101rpm, the ball size at $25 \mathrm{~mm}$ and the ball mass to sample mass ratio was kept constant at 10:1. The mill was run for $2 \mathrm{~min}$., $4 \mathrm{~min}$., $6 \mathrm{~min}$., $8 \mathrm{~min}$., and $10 \mathrm{~min}$. each. Each product was sieved for $15 \mathrm{~min}$. and the cumulative per cent mass passing $355 \mu \mathrm{m}$ and $50 \mu \mathrm{m}$ were determined.

\subsection{The effect of milling speed on breakage response}

In this set of experiments the grinding time was kept constant at 10minutes, the ball mass to sample mass ratio at 10:1 and a grinding media size of $25 \mathrm{~mm}$ was used. The critical speed of the mill, denoted $\mathrm{Vc}$, was calculated by applying (1) and found to be $131 \mathrm{rpm}$. Five milling speeds of $0.5 \mathrm{Vc}, 0.62 \mathrm{Vc}, 0.77 \mathrm{Vc}, 0.937 \mathrm{Vc}$, and $1.14 \mathrm{Vc}$ were used. The product of each test was sieved for 15 minutes and the cumulative per cent mass passing $355 \mu \mathrm{m}$ and $50 \mu \mathrm{m}$ were determined.

\section{Results and discussion}

\subsection{The effect of ball mass to sample mass ratio on grinding response of the ore}

The results of the effect of ball mass to sample mass ratio are presented in Fig. 1. The response increased gradually to a maximum of $97.474 \%$ at a ratio of $10: 1$. Production of fines was also highest at this ratio. The gradual increase in grinding output reflects increase in impact load and increase in surface area of media in contact with sample. The drop in output above the optimum was likely due to the increase in ball to ball collision which resulted in a decrease in effective impact energy available for grinding. A second reason was overriding effect of ball to ball contact above the increase in sample to ball contact.

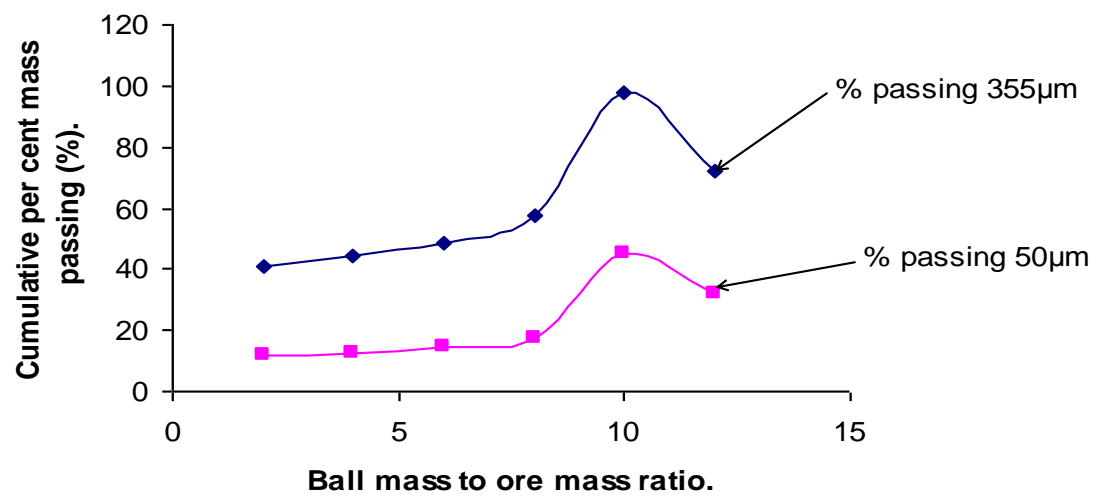

Figure 1: The effects of ball mass to sample mass ratio on ball milling output of Baban Tsauni ore. 
Fig. 1 shows that the rate of increase in the production of particles of desired size (upper curve) was higher than that of undesirable particles (lower curve). The generation of fines was almost non-sensitive to change in media mass to sample mass ratio at values below 8:1 as the curve in this region was almost horizontal.

\subsection{The effects of holding time on ball milling output}

The results of the effects of holding time on ball milling output are presented in Fig. 2. As holding time was increased from two minutes to ten minutes the per cent mass passing the liberation size increased from $21.07 \%$ to $69 \%$ while production of fines increased from $5.58 \%$ to $21.9 \%$.

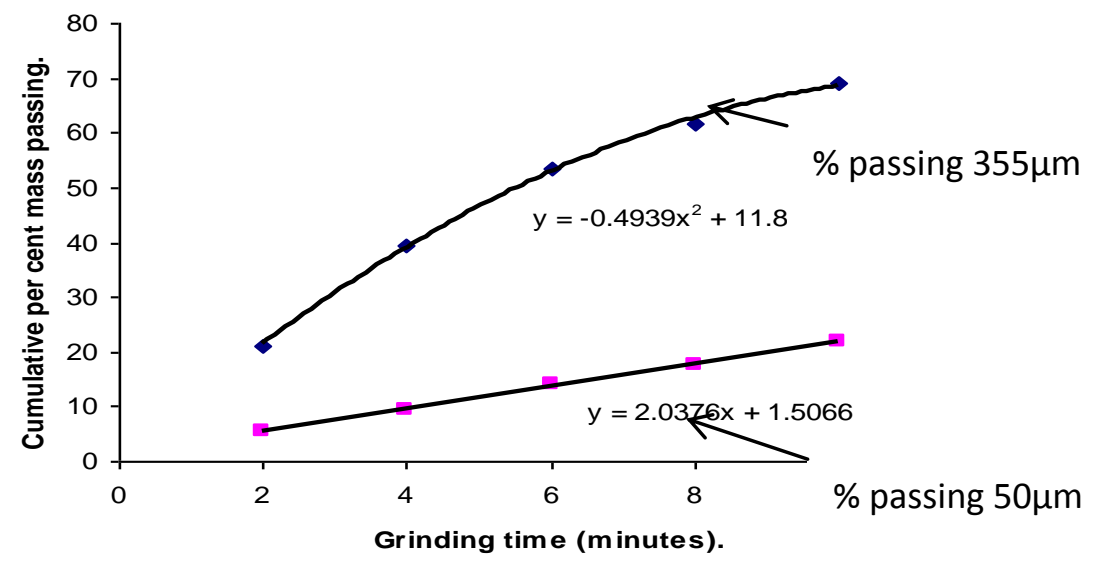

Figure 2: The effect of holding time on ball milling output.

To limit the production of fines to $10 \%$ for example the batch milling time must be limited to four minutes. The implication for closed circuit milling is that the classifier or the particle sizing system must be designed to remove materials finer than 355microns at the rate of 9.81 per cent of the feed load per minute. Fig. 2 shows that the rate of production of fine was low when compared to the per cent passing the liberation size. At 8minutes for example, the rate of fine generation was $2.0376 \% /$ minute (slope of line) while that of particles passing liberation size (gradient of curve at 8minute) was 3.94\%/minute.

The upper curve in Fig. 2 show that the gradient decreased with time. This implied that the breakage per unit time decreased with increase in holding time. Fig. 3 was obtained by calculating rates of production of particles passing the liberation size. It show that breakage per unit time dropped from 9.86\%/minute (at 2 minutes) to merely $1.96 \% /$ minute at a holding time of 10 minutes. The implication of this result is that long time grinding circuit is an energy wasting process.

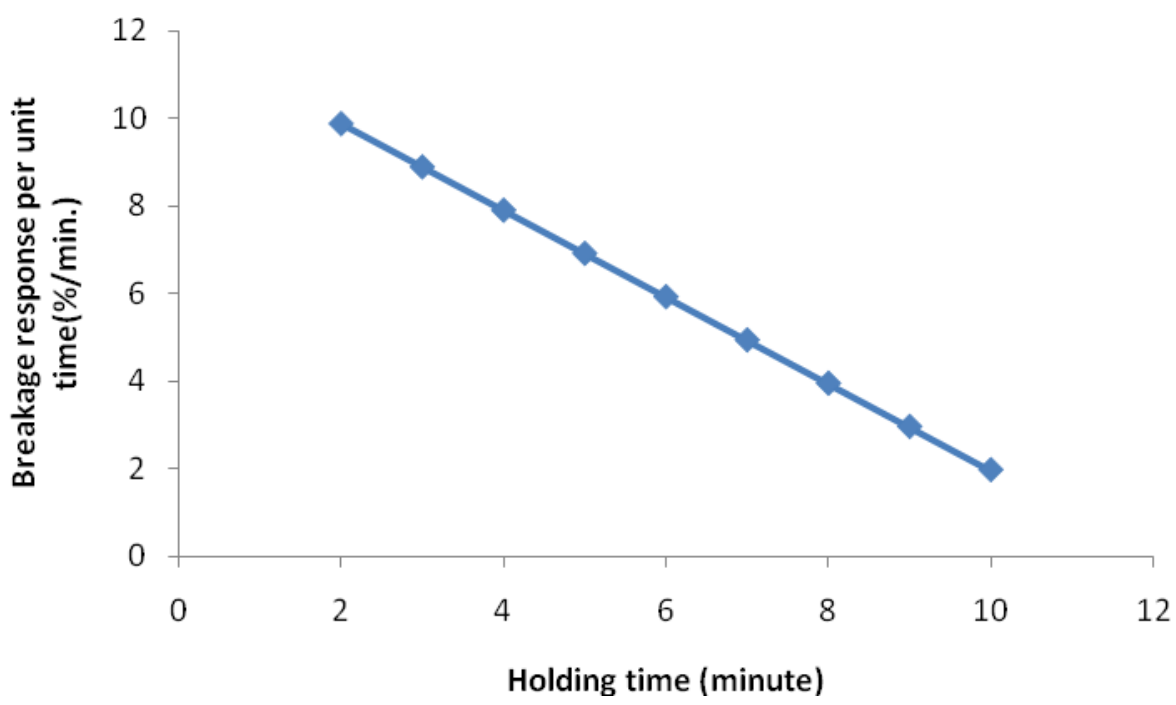

Figure 3: The rate of production of particles passing liberation size. 


\subsection{The effect of mill speed on breakage response}

The results on the effect of mill speed on grinding response are presented in Fig. 4. Mill speed was expressed in terms of critical speed (in line with common practice) by applying (1).

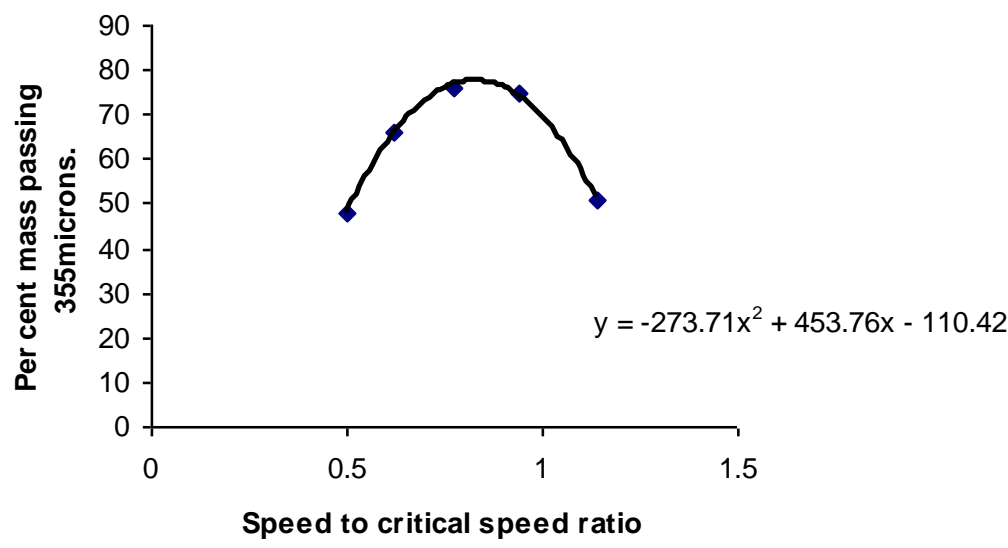

Figure 4: The effect of speed on ball milling output of Baban Tsauni ore.

The graph showed that grinding output increased with grinding speed up to a maximum value and the relationship was expressed by (2).

$$
y=-273.71 x^{2}+453.76 x-110.42
$$

The optimum grinding speed was obtained by differentiating (2) and equating to zero. This gave a value of 0.829 , which implied that the grinding output increased with speed to a maximum of $77.642 \%$ passing the liberation size at a speed of $0.829 \mathrm{~V}_{\mathrm{c}}$ and this pattern agreed with submissions in literatures [20], [24].

The output dropped to $51 \%$ at a mill speed of $1.14 \mathrm{~V}_{\mathrm{c}}$. Grinding is not expected to take place at the critical speed nor above it. Literature [20] indicates that mills have to be rotated at speeds below the critical speed for grinding to occur. The expression for critical speed (1) was derived by considering the motion of one ball [20], [3]. In a typical ball mill the position vector of the various balls from the centre differ. Thus some of the balls lost their grinding effect at the calculated critical speed of the mill. This implied that the critical speed for the second layer of balls was higher than the theoretical value which was based on the diameter of the mill. This was why grinding output did not drop to zero above critical speed as expected. However the result still agreed with the general rule that optimum grinding takes place at some speed below the critical speed and was found to be higher than $0.7 \mathrm{~V}_{\mathrm{c}}$ which is commonly used [20], [3], [24]. The implication of this result is that the optimum milling speed of each material needs to be determined rather than just operating mills below their critical speeds.

\section{Conclusion}

The results presented in this work showed that ball milling conditions affect the breakage response considerably. Production of particles of desired size increased to an optimum value with increase in the ratio of media mass to sample mass. The grinding response decreased with increase in holding time and the quality measured in term of fines generated also decreased with increase in milling time. The milling output attained an optimum value at an optimum speed of $0.829 \mathrm{Vc}$. Optimum ball milling response can only be attained with optimum grinding speed, optimum media mass to sample mass ratio and short grinding circuit.

\section{References}

[1] Levin, J., Indicators of grindability and grinding efficiency. J. S. Afr. Inst. Min. Metall., 92 (10), 1992, 283-290,

[2] Deniz, V. Relationships Between Bond's Grindability (Gbg) and Breakage Parameters of Grinding Kinetic on Limestone. Proceedings of $18^{\text {th }}$ International Mining Congress and Exhibition of Turkey-IMCET, 2003, 451-456.

[3] Wills, B.A. and Napier-Munn, T. Wills'Mineral Processing Technology-An Introduction to the Practical Aspects of Ore Treatment and Mineral Recovery. Seventh Edition. (Amsterdam: Elsevier Science and Technology Books), 2006, P450.

[4] Doll, A., and Barratt, D. Grinding: Why So Many Tests? 43 ${ }^{\text {rd }}$ Annual Meeting of the, Canadian Mineral Processors, Ottawa, Ontario, Canada. January 18 to 20, 2011.

[5] Man, Y.T. Technical Note: Why is the Bond Ball Mill Grindability Test done the way it is done? The European Journal of Mineral Processing and Environmental Protection 2(1), 1303-0868, 2002, 34-39.

[6] Aksani, B., and Sönmez, B. Simulation of Bond Grindability Test by Using Cumulative Based Kinetic Model, Minerals Engineering, 13 (6), 2000, 673. 
[7] Deniz, V., and Ozdag, H., “A New Approach to Bond Grindability and Work Index: Dynamic Elastic Parameters", Minerals Engineering, 16(3), 2003, 211-217.

[8] Ozkahraman, H.T..A Meaningful Expression Between Bond Work Index, Grindability Index and Friability Value, Minerals Engineering, 18(10), 2005, 1057-1059.

[9] Partyka, T., and Yan, D., Fine Grinding in a Horizontal Ball Mill, Minerals Engineering, 20(4), $2007,320-326$.

[10] Ścieszka S., .Grzegorzek, W. and Żołnierz, M. Laboratory methods for combined testing of abrasiveness, grindability and wear in coal processing systems, Journal of Scientific Problems of Machines Operation and Maintenance, 4 (164), 2010, 19-35.

[11] Muhammad, I.A., Abdul, G.P., and Abdul, H.M., Work index and grinding energy assessment of Dilband iron ore, Pakistan, Mehran University Research Journal of Engineering \& Technology, 30(1), 2011, 29-34.

[12] Magdalinovic, N., Magdalinovic, S, Jovanovic, R. and Stanujkic, D., Is there a material constant which characterises mineral resources grindability? Annual of the University of Mining and Geology "St. Ivan Rilski", 54(Part II), Mining and Mineral processing, 2011, 116-117

[13] Egbe, E.A.P. Characterization and Beneficiation of Baban Tsauni, Gwagwalada Ore, Nigeria, Thesis Submitted in Partial Fulfilment for the Award of the Degree of Doctor of Philosophy, Department of Mechanical Engineering, School of Engineering and Engineering Technology, Federal University of Technology, Minna, Nigeria, 2012.

[14] Fuerstenau, D.W., Lutch, J.J. and De, A., The effect of ball size on the energy efficiency of hybrid high-pressure roll mill/ball mill grinding, Powder Technol. 105, 1999, 199-204.

[15] Kotake, N., Daibo, K., Yamamoto, T., Kanda, Y., , Experimental investigation on a grinding rate constant of solid materials by a ball mill - effect of ball diameter and feed size, Powder Technol. 143- 144, 2004 196- 203.

[16] Trumic, M., Magdalinovic, N., Trumic, G., , The model for optimal charge in the ball mill, Journal of Mining and Metallurgy A( 43), 2007,19-32.

[17] Katubilwa, F. M. and Moys, M.H., , Effect of ball size distribution on milling rate, Miner. Eng. 22, 2009, 1283-1288

[18] Erdem, A.S. and Ergun, S.L. The effect of ball size on breakage rate parameter in a pilot scale ball mill, Miner. Eng. 22, 2009, 660664

[19] Magdalinovic, N., Trumic, M., Trumic, M. and Andric, L. The optimal ball diameter in a mill, Journal of Physicochemical Problems of Mineral Processing, 48(2), 2012, 329-339.

[20] Gupta, A. and Yan, D.S. Mineral Processing Design and Operation- An Introduction. Amsterdam, Elsevier B. V., 2006, P693.

[21] Sahoo, A. and Roy, G. K. Correlations for the Grindability of the Ball Mill As a Measure of Its Performance, Asia Pac. J. of Chem. Engineering, 3 (2), 2008, 230-235.

[22] Sahyoun, C., Kingman, S.W. and Rowson, N.A., High powered microwave treatment of carbonate copper ore, The European Journal of Mineral Processing and Environmental Protection 4(3), 2004, 175-182.

[23] Ipek, H., Goktepe, F. Determination of grindability characteristics of zeolite, Physicochem. Probl. Miner. Process. 47, 2011, 183192

[24] Damisa, E.O.A. Beneficiation Potentials of Nahuta Lead Deposit, Bauchi State, Nigeria, Thesis Submitted in Partial Fulfilment for the Award of the Degree of Doctor of Philosophy, Department of Metallurgical Engineering ,Faculty of Engineering, Ahmadu Bello University, Zaria, Nigeria, 2008 